\title{
Quantile momentum
}

\author{
Yongchang Feng ${ }^{\dagger}$, Rong Chen*, and Gilbert W. Bassett
}

A stock portfolio based on momentum strategies buys stocks that have recently performed well and sells (or shorts) stocks that have recently performed poorly. The most commonly used measure of past performance (momentum) of a stock is its average return over the previous 2 to 12 months. In this paper, we propose a different set of measures of past performance based on the quantiles of past returns and investigate the performance of momentum portfolios based on such measures. We also introduce a robust version of the proposed quantile momentum by locally smoothing data before ranking. It is shown that the portfolios under these proposed alternative momentum measures can have very different returns from one another, as well as from the standard portfolio based on the average. We also consider the correlations of portfolio returns between the alternative strategies and their combinations. A well known feature of momentum portfolios is that they carry incidental $\beta$ exposures depending on whether the market has been rising or falling. A practical matter for portfolio managers is the extent to which momentum can be improved by neutralizing the incidental $\beta$ exposures. We investigate how the various definitions of momentum are likely to affect the incidental $\beta$ exposures in long and short momentum portfolios.

Keywords AND PHRASES: Momentum strategies, Betasensitive Portfolio, Sharpe ratio, Quantile Momentum, Price inefficiency.

\section{INTRODUCTION}

It has been widely documented that stock prices exhibit momentum behavior. Stock momentum is loosely defined as the observed behavior that a stock that has performed well recently tends to continue to perform well and a stock that has performed poorly recently tends to continue to perform poorly. To gain excess

${ }^{*}$ Corresponding author.

†Yongchang Feng is at the Department of Business Statistics and Econometrics, Guanghua School of Management, Peking University. Yongchang Feng's research is supported by the GSM-Wang-Shan Ph.D. Exchange Fellowship and UIC-CME International Center for Futures and Derivatives. Rong Chen is Professor, Department of Statistics, Rutgers University and Department of Business Statistics and Econometrics, Peking University. Rong Chen's research is sponsored in part by NSF grants DMS 0244541 and NIH grant R01 Gm068958. Gilbert W. Bassett is Professor, Department of Finance, University of Illinois at Chicago. return based on the momentum behavior, a momentum strategy ranks the stocks according to their recent performance and forms a portfolio that longs the top ranked stocks and shorts the bottom ranked stocks (Levy 1967, Jegadeesh and Titman 1993, Jegadeesh and Titman 2001, Fama and French 1996, Moskowitz and Grinblatt 1999, Lewellen 2002, George and Hwang 2004, Rachev, Jašić, Stoyanov, and Fabozzi 2007). The excess return of such strategies has been documented and extensively investigated. It has been recognized that, after discounting the incidental exposure due to confounding risk factors such as size or value of the stock, momentum is important and non-negligible.

Momentum was noted in academia as early as Levy (1967) and celebrated in the form of a relative strength indicator by equity traders for a long time. It is different from long-term (three to five-year) or short-term (one week or month) market over-reaction and mean-reversion, where stock returns in the future are observed to be negatively correlated with that in the immediate past (Poterba and Summers 1988, Jegadeesh 1990, Lehmann 1990, Lo and MacKinlay 1990). A mean-reversion or contrarian strategy would buy the stocks that performed poorly in the immediate past and sell the stocks that performed well in the immediate past. The holding period and evaluation period of the past are usually of the same length. Momentum strategies buy the stocks that performed well in the past for a period of intermediate length (say one year), but the holding period is often short (say one month).

Jegadeesh and Titman (1993) used average returns in a look-back window as a measure of momentum and formed decile portfolios as well as a zero-cost momentum strategy that buys the stocks in top deciles and sells those in the bottom deciles. Based on the performance of different variations of the strategy, including different length of the look-back window and the length of holding periods, they found that momentum portfolios consistently produce positive returns.

To explain the source of momentum profits, Jegadeesh and Titman (1993) proposed two models. The first is a simple one-factor model requiring instantaneous stock exposure to the factor. Under this model, three possible sources of momentum returns are identified: (i) cross-sectional dispersion of expected returns, (ii) serial correlation of idiosyncratic returns, and (iii) exposure to factor returns. For example, if factor returns are positively correlated with momentum then momentum portfolios will tend to pick up stocks with large betas. An alternative assumption is to allow lagged 
response to market movements, such as lead-lag relationship (Lo and MacKinlay 1990). By examining the betas, market capitalization, serial correlation of market returns or market model residuals, and the regression coefficient of momentum returns on squared factor returns, Jegadeesh and Titman (1993) argued that idiosyncratic return is the most probable source of momentum profits. The conclusion implies market under-reaction to firm-specific news.

Fama and French (1996) also considered momentum. They confirmed the findings of Jegadeesh and Titman (1993) by forming decile portfolios based on performance from the previous 12 to 2 months. Although their threefactor model of size and value captures most of the CAPM average-return anomalies, it misses momentum. Moskowitz and Grinblatt (1999) argued that most of the momentum profits comes from momentum behavior on the industry level. Lewellen (2002) found that size and value portfolios exhibit momentum as strong as that in individual stocks and industries, and attributed momentum to excess stock covariance.

A key component in constructing a momentum portfolio is the momentum measure $(\mathrm{MoM})$. It serves as a quantitative measure of the recent performance of the stocks and is used to rank the stocks. In most of the previous studies, the average monthly return in a look-back window is used for MoM. We denote it as MoM(Mean). The most commonly used look-back window is from t-12 to t-2. The most recent month is often excluded on account of short-term reversal, see Jegadeesh and Titman (1993).

Other MoMs have been proposed. George and Hwang (2004) considered momentum returns based on the difference between the 52-week high and the current price of a stock. Ranking stocks on this difference and forming corresponding decile portfolios, they found momentum returns comparable with Jegadeesh and Titman (1993) and Moskowitz and Grinblatt (1999). Recently, Rachev, Jašić, Stoyanov and Fabozzi (2007) proposed ranking the stocks using risk-adjusted performance measures such as the Sharpe Ratio, STARR ratio and R-ratio. They found that the portfolios based such MoMs outperform the benchmark using $\operatorname{MoM}($ Mean $)$ in most situations.

The results of George and Hwang (2004) and Rachev, Jašić, Stoyanov, and Fabozzi (2007) show that different measures of momentum produce different profitability and hence there may be alternative mechanisms driving momentum. For example, momentum profits may be partially due to trader's under-reaction to firm-specific news (Jegadeesh and Titman, 1993). Alternatively there may be reluctance to change prices when the price is close to its 52-week high, as observed by George and Hwang (2004). However, there are no clear indications of a universal cause.

In this paper, we investigate a new set of MoMs and study the performance of momentum portfolios based on these MoMs. Specifically we introduce quantile MoMs, which are based on the quantiles of the returns in a look-back window. These MoMs produce rankings that are usually very different than the one based on average returns. For example, MoM(Max) measures the recent performance of a stock by its maximum monthly return in the look-back window. A momentum portfolio based on $\operatorname{MoM}(\operatorname{Max})$ buys the stocks with the highest single month return in the look-back window and shorts the stocks whose highest single month return is the smallest. Such a portfolio aggressively seeks stocks that have had large single month gains in the past. These stocks may not be ranked highly under a measure based on average returns.

The rest of the paper is organized as follows. Section 2 formally introduces quantile momentum, discusses its properties and provides some perspectives under a simple CAPM model. A more robust version of the quantile momentum is also introduced. Empirical evidence is presented in section 3 , with detailed consideration of the tuning parameters and the correlations between the returns generated by the alternative strategies. Section 4 concludes the paper with a brief summary.

\section{QUANTILE MOMENTUM}

\subsection{Definition}

We construct a quantile MoM as follows: Let $r_{i, t-1}, \ldots, r_{i, t-d}$ be the (monthly) return of the $i$-th stock in the previous $d$ months (the look-back window). Define $\operatorname{MoM}\left(\mathrm{Q}_{\theta}\right)$ as

$$
\operatorname{MoM}\left(\mathrm{Q}_{\theta}\right)_{i, t}=Q_{\theta}\left(r_{i, t-2}, \ldots, r_{i, t-d}\right),
$$

the $\theta$-th quantile of $r_{t-2}, \ldots, r_{t-d}$. Here we omit $r_{t-1}$ in the definition to avoid the well documented reversal effect.

A long $\operatorname{MoM}\left(\mathrm{Q}_{\theta}\right)$ momentum portfolio is constructed by ranking the stocks according to $\operatorname{MoM}\left(\mathrm{Q}_{\theta}\right)$ and buying the top $p$ percent of the top ranked stocks. A short $\operatorname{MoM}\left(\mathrm{Q}_{\theta}\right)$ momentum portfolio sells the bottom $p$ percent of the stocks. A long-short portfolio merges the two portfolios with equal weights.

Two particularly interesting and more intuitively understandable quantile MoMs are $\operatorname{MoM}(\operatorname{Max})$ and $\operatorname{MoM}($ Min), corresponding to $\theta=1$ and $\theta=0$. MoM(Max) ranks the stocks according to their best single month return in the look-back window. Hence a short MoM(Max) portfolio effectively adopts a minimax strategy. It shorts the stocks with smallest maximum single month returns in the look-back window. These stocks tend to be the ones with consistent poor performance and small volatility. On the other hand, a long $\operatorname{MoM}(\operatorname{Min})$ portfolio is maximin, buying the stocks with largest minimum single month returns. Hence it is a conservative and defensive strategy, picking the stocks that were good in the worst cases. The long MoM(Max) portfolio is super aggressive in that it buys the stocks that have had large single month returns. The short MoM(Min) portfolio is also aggressive, shorting stocks with the largest single month loss. 


\subsection{Incidental beta exposure}

A well known feature of momentum portfolios is that they carry incidental $\beta$ exposure depending on whether the market has been rising or falling. In rising markets, high $\beta$ stocks tend to do better than low $\beta$ stocks. So if within the lookback window the market was rising, the long-short momentum portfolios based on the standard momentum definition would have positive $\beta$. Conversely, in falling markets momentum portfolio will tend to have negative $\beta$. A practical issue for portfolio managers is the extent to which momentum can be improved by neutralizing these incidental $\beta$ exposures. In the following, we consider the incidental $\beta$ exposures of quantile momentum portfolios.

Similar to Jegadeesh and Titman (1993), we use a one factor model to analyze momentum portfolios. Assume for stock $i$, the return $r_{i, t}$ follows the one factor CAPM model

$$
r_{i, t}=\alpha_{i}+\beta_{i}\left(M_{t}-r_{f}\right)+e_{i, t}
$$

where $M_{t}$ is the market return at time $t$, assumed constant to all stocks. $r_{f}$ is the risk-free rate.

We first consider the long-short portfolio under $\operatorname{MoM}(\operatorname{Max})$. When there is at least one large positive market return $M_{t-s}$ in the look-back window, the top ranked stocks ranked by $\operatorname{MoM}(\operatorname{Max})$ will tend to be those with the largest $\beta$. Conversely, the bottom ranked stocks are those with the smallest $\beta$. Hence $\operatorname{MoM}(\operatorname{Max})$ ranking tends to be similar to the $\beta$ ranking. A long-short $\mathrm{MoM}(\mathrm{Max})$ portfolio will have positive beta exposure and perform well when the market return continues to be positive. In contrast, the MoM(Mean) portfolio will be comparatively less $\beta$ sensitive because it depends on the average of the market returns, which can be small even when there is one very large single month positive market return in the look-back window. Note that during the past 58 years there have been no cases that S\&P500 had negative returns for 11 consecutive months and $80 \%$ of the time the maximum single month market return within a 11 month period is larger than $4 \%$. Hence most of the time the $\operatorname{MoM}(\operatorname{Max})$ portfolio carries a strong positive incidental beta exposure. On the other hand, there have been only $35 \%$ of the time when the average return is larger than $1.2 \%(4 \% / \sqrt{11})$, during which $\operatorname{MoM}($ Mean) portfolio carries a strong positive incidental beta exposure.

In flat and small volatility market periods when market returns in the look-back window are all around zero, the $\operatorname{MoM}(\operatorname{Max})$ will be $\beta$ neutral and be influenced mainly by $\alpha_{i}+\max \left(e_{i, t-2}, \ldots, e_{i, t-d}\right)$. In this case, $\operatorname{MoM}($ Mean $)$ is $\beta$ neutral and ranks the stocks approximately by $\alpha_{i}+\operatorname{mean}\left(e_{i, t-2}, \ldots, e_{i, t-d}\right)$. It is clear that $\max \left(e_{i, t-2}, \ldots, e_{i, t-d}\right)$ from MoM(Max) masks the $\alpha$ ranking more severely than mean $\left(e_{i, t-2}, \ldots, e_{i, t-d}\right)$ from $\operatorname{MoM}($ Mean). Hence MoM(Mean) tends to reflect the alpha ranking stronger than $\operatorname{MoM}(\operatorname{Max})$. Again, in the past 58 years there are less than $20 \%$ of the times when the maximum market return is less than $4 \%$ within a 11 month period, but $55 \%$ of the times when the absolute average return
Table 1. Alpha and beta sensitivity of quantile momentum portfolio

\begin{tabular}{|c|c|c|c|}
\hline & \multicolumn{3}{|c|}{ Market Condition } \\
\hline $\operatorname{MoM}(\operatorname{Max})$ & $\mathrm{L}$ & $\mathrm{S}$ & \\
\hline Top & large $\beta$ & large $\alpha$ & \\
\hline Bottom & small $\beta$ & small $\alpha$ & \\
\hline Top-Bottom & $\beta>0$ & $\beta \approx 0, \alpha>0$ & \\
\hline MoM(Min) & l & $\mathrm{s}$ & \\
\hline Top & small $\beta$ & large $\alpha$ & \\
\hline Bottom & large $\beta$ & small $\alpha$ & \\
\hline Top-Bottom & $\beta<0$ & $\beta \approx 0, \alpha>0$ & \\
\hline MoM(mean) & + & $\cdot$ & - \\
\hline Top & large $\beta$ & large $\alpha$ & small $\beta$ \\
\hline Bottom & small $\beta$ & small $\alpha$ & large $\beta$ \\
\hline Top-Bottom & $\beta>0$ & $\beta \approx 0, \alpha>0$ & $\beta<0$ \\
\hline
\end{tabular}

Alpha and beta sensitivity characteristics of the top and bottom decile portfolios and long-short portfolios at various market conditions in the look-back window, including market with at least one large positive return (L), flat market with a small maximum market return (S), market with at least one large magnitude negative return (l), flat market with a small magnitude minimum negative market return $(\mathrm{s})$, large average market return $(+)$, flat market with small absolute average market return $(\cdot)$, large magnitude negative average market return $(-)$.

is less than $1.2 \%(4 \% / \sqrt{11})$. Hence $\operatorname{MoM}($ Mean $)$ portfolio is more often to have a strong incidental alpha exposure.

In a declining market when there is at least one monthly market return that is positive and near zero, the $\operatorname{MoM}(\operatorname{Max})$ portfolio remains $\alpha$ sensitive and $\beta$ neutral. In contrast $\operatorname{MoM}($ Mean) will tend to buy stocks with small $\beta$ and short stocks with large $\beta$, hence having a negative beta exposure. This happened about $8 \%$ of the time in the past 58 years.

Similar arguments hold for MoM(Min) portfolios and mixed MoM(Min) and MoM(Max) portfolios. Table 1 summarizes the relationship between incidental beta as a function of recent market performance for the various momentum measures. We also report the frequency of each market condition observed in the past 58 years (from January 1950 to September 2008) in Table 2 for reference. There are several interesting observations from reading the two tables jointly. For example, there are $36 \%$ of the time the market is in the condition of " $L \cdot l$ ". This is a volatile condition in which the maximum single month market return is over $4 \%$ and the minimum return is less than $-4 \%$. However, the average return is between $-1.2 \%$ and $1.2 \%$. In this market, the portfolio based on $\operatorname{MoM}(\operatorname{Max})$ has positive $\beta$ exposure, that based on $\operatorname{MoM}($ Min) has negative $\beta$ exposure, and that based on Mom(Mean) is $\beta$ neutral. We also observe that there are $17 \%$ of the time the market in the condition of $L+s$, in which the $\operatorname{MoM}(\operatorname{Max})$ and $\operatorname{MoM}($ mean $)$ portfolios have positive beta exposures while the MoM(Min) portfolio is beta neutral and alpha sensitive. Such properties suggest adaptive strategies in choosing different momentum portfolios in different market conditions. 
Table 2. Frequency of market conditions from January 1950 to September 2008 using monthly S\&P 500 returns

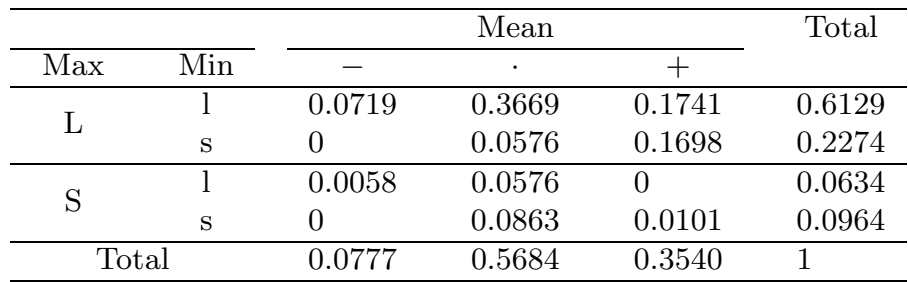

Frequency of market conditions from January 1950 to September 2008 using monthly S\&P 500 returns. Conditions include maximum market return in a 11-month look-back window larger than $4 \%(\mathrm{~L})$, less than $4 \%(\mathrm{~S})$, minimum market return less than $-4 \%$ (1), larger than $-4 \%(\mathrm{~s})$, average market return larger than $1.2 \%=4 \% / \sqrt{11}(+)$, less than $-1.2 \%(-)$ and in between $(\cdot)$.

\subsection{Locally smoothed quantiles}

Quantile estimators with a small number of observations can be sensitive to outliers such as one-time event, shortlived rumors and other short term shocks. Its impact can also be seen from a comparison between $\operatorname{MoM}(\operatorname{Max})$ and $\operatorname{MoM}($ Mean) under flat market conditions. In this case, both MoMs reflect the $\alpha$ ranking. However, MoM(Mean) estimates $\alpha_{i}$ more accurately as the noises $e_{i, t-d}$ are averaged. On the other hand, the difference between $\operatorname{MoM}(\operatorname{Max})$ and $\alpha_{i}$ is $\max \left(e_{i, t-2}, \ldots, e_{i, t-d}\right)$ hence $\operatorname{MoM}(\operatorname{Max})$ tends to choose the stocks with large volatility. To reduce this problem while preserving the good properties of quantile MoMs, we propose locally smoothed quantiles. Specifically, let $r_{i, t}^{*}=k^{-1} \sum_{s=0}^{k-1} r_{i, t-s}$ be the smoothed return series with smoothing window size $k$. For $k<d$, define

$$
\operatorname{MoM}\left(\mathrm{SQ}_{\theta}\right)_{i, t}=Q_{\theta}\left(r_{i, t-2}^{*}, \ldots, r_{i, t-d+k-1}^{*}\right)
$$

Note that when $k=d-1, \operatorname{MoM}\left(\mathrm{SQ}_{\theta}\right)$ reduces to $\mathrm{MoM}(\mathrm{Mean})$ with look-back window size $d$. Hence $\operatorname{MoM}\left(\mathrm{SQ}_{\theta}\right)$ with large $k$ tends to perform similar to $\operatorname{MoM}($ Mean $)$. When $k=1, \operatorname{MoM}\left(\mathrm{SQ}_{\theta}\right)$ is the same as $\operatorname{MoM}\left(\mathrm{Q}_{\theta}\right)$.

\section{EMPIRICAL PERFORMANCES}

\subsection{Data and trading strategies}

We consider all stocks in CRSP with monthly returns. The sample period is January 1980 to December 2006. To be included in the universe at time $t$, a stock should have a return for $t-2$ and a price for the end of $t-13$ and any missing values from $t-12$ to $t-3$ should only be due to missing prices. To be included into a decile portfolio, a stock must also have a market equity at the end of $t-1$. We form decile portfolios using various MoMs. Traditionally decile portfolios are constructed by grouping the ranked stocks into ten slices of equal size, using order statistics as the breakpoints. However, previous research such as (Fama and French 1996) first determine the breakpoints using the order statistics within NYSE stock universe, then group all stocks in the CRSP universe into ten decile portfolios according to the NYSE breakpoints. Hence the deciles are not necessarily of equal size. To make our results comparable, we follow such a convention.

We use MoM(Mean) based on a look-back window from $t-2$ to $t-12$ as our benchmark. Conventional momentum strategy uses MoM(Mean) to rank the stocks and form a momentum portfolio by buying the stocks in top decile and shorting/selling those in the bottom decile. For comparison, we also consider the risk-compensated MoM based on the Sharpe Ratio, denoted as MoM(SR).

In this study, we consider $\operatorname{MoM}\left(\mathrm{SQ}_{\theta}\right)$ with five different $\theta$ 's, corresponding to $\theta=0,0.25,0.5,0.75$ and 1 , labelled as $\operatorname{MoM}(\mathrm{SMin}), \operatorname{MoM}\left(\mathrm{SQ}_{.25}\right), \operatorname{MoM}(\mathrm{SQ} .50), \operatorname{MoM}\left(\mathrm{SQ}_{.75}\right)$ and $\operatorname{MoM}(\mathrm{SMax})$, respectively. We also consider smoothing window size $k$ from 1 to 7 . In particular, when $k=1$, $\operatorname{MoM}\left(\mathrm{SQ}_{\theta}\right)$ is the original $\operatorname{MoM}\left(\mathrm{Q}_{\theta}\right)$. They are labelled as $\operatorname{MoM}(\operatorname{Min}), \operatorname{MoM}\left(Q_{.25}\right), \operatorname{MoM}\left(Q_{.50}\right), \operatorname{MoM}\left(Q_{.75}\right)$ and $\operatorname{MoM}(\operatorname{Max})$, respectively. To obtain a clearer picture of the portfolio behavior, we separate the top decile and bottom decile portfolios. For long-short portfolio, we long the top decile portfolio and short the bottom decile portfolio with equal weights. In addition, we also consider equally weighted and value-weighted portfolios where the selected stocks in the portfolios are given equal weights or weighted by their corresponding market values, respectively.

\subsection{Performances}

We evaluate the performance of the portfolios using the annualized average monthly return, return variation and Sharpe Ratio, with portfolios rebalanced at the beginning of each month.

\subsubsection{Impact of the smoothing window size}

Figure 1 shows the annualized average portfolio returns of long-short portfolios under various MoMs and smoothing window size. It shows that the window size $k$ is indeed an important factor.

For the value-weighted portfolios in Figure 1(a) and 1(e), we observe that the $\mathrm{MoM}\left(\mathrm{SQ}_{.25}\right)$ portfolio performs the best with $k$ between 3 and 6 , and outperforms those using $\operatorname{MoM}($ Mean $)$ and $\operatorname{MoM}(\mathrm{SR})$. The best performance is achieved by $\operatorname{MoM}\left(\mathrm{SQ}_{.25}\right)$ when $k=4$. MoM(SMin) exhibits sub-optimal performance for small smoothing window size but superior to $\operatorname{MoM}\left(\mathrm{SQ}_{.25}\right)$ when $k=7$.

For equally weighted portfolios shown in Figure 1(b) and $1(\mathrm{f})$, the $\operatorname{MoM}\left(\mathrm{SQ}_{.25}\right)$ portfolio continues to outperform those of MoM(Mean) and other MoMs for $k$ from 2 to 5 except $\operatorname{MoM}(\mathrm{SR})$.

We also observe that the equally weighted long-short momentum portfolio $\mathrm{MoM}(\mathrm{SR})$ outperforms all others on both 


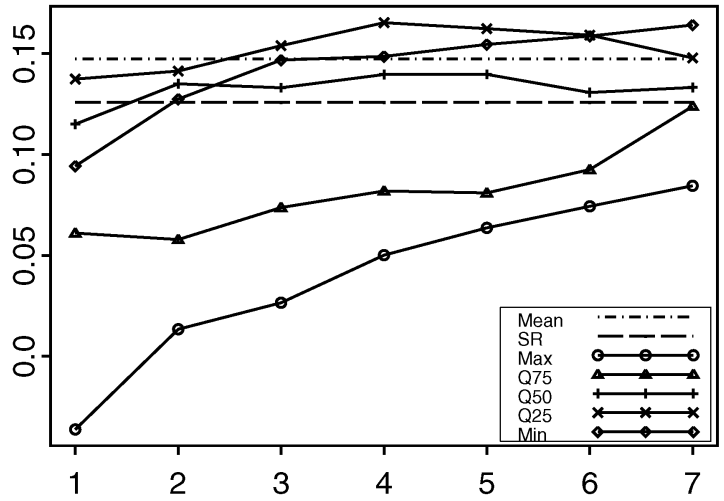

(a) Annualized Return versus Smoothing Window Size $(\mathrm{VW})$

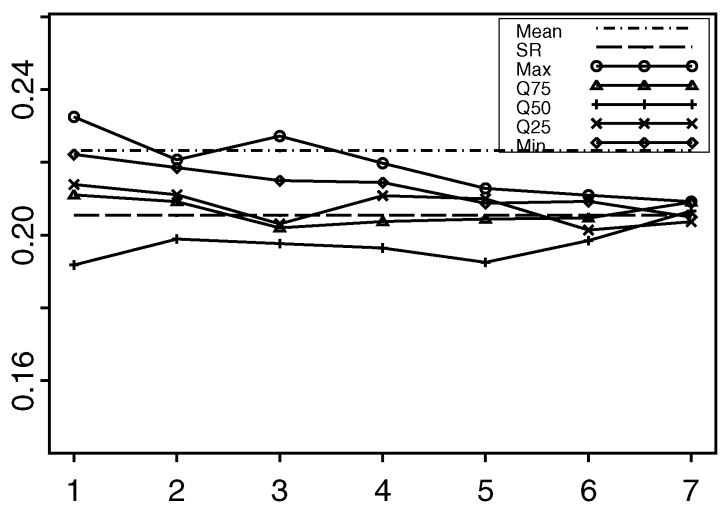

(c) Annualized Volatility versus Smoothing Window Size $(\mathrm{VW})$

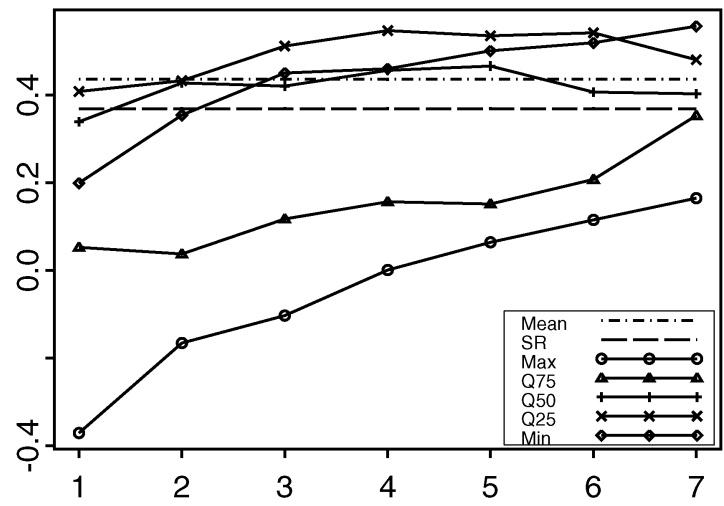

(e) Sharpe Ratio versus Smoothing Window Size (VW)

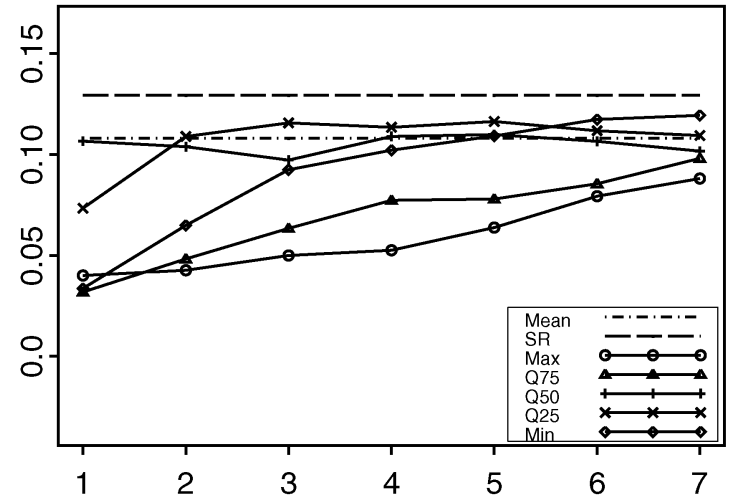

(b) Annualized Return versus Smoothing Window Size $(\mathrm{EW})$

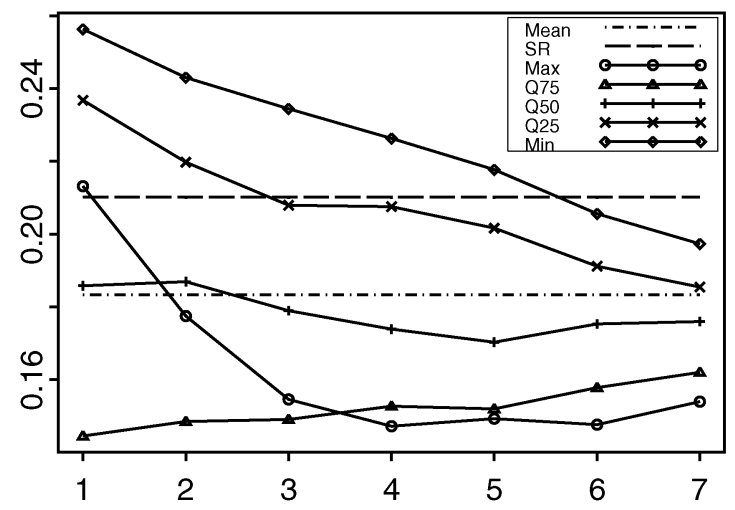

(d) Annualized Volatility versus Smoothing Window Size (EW)

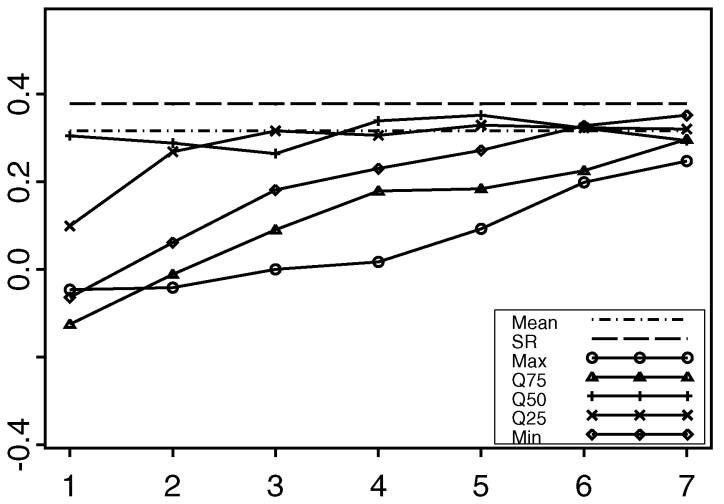

(f) Sharpe Ratio versus Smoothing Window Size (EW)

Figure 1. Plot of annualized return, volatility, and Sharpe Ratio versus smoothing window size $(k)$ for different smooth quantile momentum long-short value-weighted (VW) portfolios and equally weighted (EV) portfolios.

average return and Sharpe Ratio. It indicates that the riskcompensated MoM works better for small stocks. This is also supported by the $\operatorname{MoM}\left(\mathrm{SQ}_{.50}\right)$ portfolio that has second largest Sharpe Ratio for $k=4$ and $k=5$. Note that this is different from Rachev, Jašić, Stoyanov and Fabozzi (2007). They found that for equally weighted long-short momentum portfolio, MoM(SR) underperforms MoM(Mean).
Possible reasons for the discrepancy may be multi-fold, including the differences in sample frequency, look-back window, and holding duration.

For clear presentation, in the following we use $k=1$ and $k=4$ in all $\operatorname{MoM}\left(\mathrm{SQ}_{\theta}\right)$ constructions, respectively. Results based on other smoothing window sizes are available upon request. 
Table 3. Annualized performances of quantile momentum portfolios

\begin{tabular}{|c|c|c|c|c|c|c|c|c|c|c|c|c|c|}
\hline Weight & Portfolio & Statistics & MoM(Mean) & $\operatorname{MoM}(\mathrm{SR})$ & $\operatorname{MoM}(\operatorname{Max})$ & $\operatorname{MoM}(Q .75)$ & $\operatorname{MoM}(Q .50)$ & $\operatorname{MoM}(Q .25)$ & MoM(Min) & MaxMin & MinMax & $75 / 25$ & $25 / 75$ \\
\hline \multirow{9}{*}{ VW } & \multirow{3}{*}{$\mathrm{T}$} & return & $18.81 \%$ & $18.94 \%$ & $11.30 \%$ & $16.09 \%$ & $17.15 \%$ & $17.26 \%$ & $16.54 \%$ & - & - & - & - \\
\hline & & volatility & $22.20 \%$ & $17.98 \%$ & $26.58 \%$ & $25.72 \%$ & $20.61 \%$ & $16.36 \%$ & $13.52 \%$ & - & - & - & - \\
\hline & & SharpeR & 0.622 & 0.775 & 0.237 & 0.431 & 0.590 & 0.749 & 0.854 & - & - & - & - \\
\hline & \multirow{3}{*}{ B } & return & $4.09 \%$ & $6.36 \%$ & $14.93 \%$ & $9.98 \%$ & $5.65 \%$ & $3.53 \%$ & $7.11 \%$ & - & - & - & - \\
\hline & & volatility & $23.70 \%$ & $19.95 \%$ & $11.90 \%$ & $16.08 \%$ & $22.93 \%$ & $26.67 \%$ & $26.66 \%$ & - & - & - & - \\
\hline & & SharpeR & -0.039 & 0.068 & 0.834 & 0.310 & 0.028 & -0.055 & 0.079 & - & - & - & - \\
\hline & \multirow{3}{*}{ T-B } & return & $14.73 \%$ & $12.58 \%$ & $-3.62 \%$ & $6.11 \%$ & $11.51 \%$ & $13.73 \%$ & $9.42 \%$ & $4.19 \%$ & $1.61 \%$ & $12.57 \%$ & $7.28 \%$ \\
\hline & & volatility & $22.32 \%$ & $20.54 \%$ & $23.25 \%$ & $21.10 \%$ & $19.18 \%$ & $21.39 \%$ & $22.22 \%$ & $10.28 \%$ & $11.08 \%$ & $13.25 \%$ & $16.57 \%$ \\
\hline & & SharpeR & 0.436 & 0.369 & -0.371 & 0.053 & 0.339 & 0.408 & 0.199 & -0.079 & -0.306 & 0.571 & 0.138 \\
\hline \multirow{9}{*}{ EW } & \multirow{3}{*}{$\mathrm{T}$} & return & $22.77 \%$ & $24.12 \%$ & $17.07 \%$ & $17.96 \%$ & $22.20 \%$ & $19.72 \%$ & $16.84 \%$ & - & - & - & $\overline{-}$ \\
\hline & & volatility & $23.32 \%$ & $17.20 \%$ & $26.91 \%$ & $25.77 \%$ & $22.09 \%$ & $13.85 \%$ & $9.24 \%$ & - & - & - & - \\
\hline & & SharpeR & 0.762 & 1.111 & 0.449 & 0.503 & 0.778 & 1.063 & 1.281 & - & - & - & - \\
\hline & \multirow{3}{*}{ B } & return & $11.97 \%$ & $11.18 \%$ & $13.06 \%$ & $14.77 \%$ & $11.53 \%$ & $12.38 \%$ & $13.48 \%$ & - & - & - & - \\
\hline & & volatility & $28.10 \%$ & $24.84 \%$ & $10.00 \%$ & $19.48 \%$ & $28.69 \%$ & $29.93 \%$ & $29.63 \%$ & - & - & - & - \\
\hline & & SharpeR & 0.248 & 0.249 & 0.806 & 0.502 & 0.228 & 0.246 & 0.286 & - & - & - & - \\
\hline & \multirow{3}{*}{ T-B } & return & $10.80 \%$ & $12.93 \%$ & $4.01 \%$ & $3.19 \%$ & $10.66 \%$ & $7.34 \%$ & $3.36 \%$ & $3.59 \%$ & $3.78 \%$ & $5.58 \%$ & $4.95 \%$ \\
\hline & & volatility & $18.33 \%$ & $21.01 \%$ & $21.32 \%$ & $14.45 \%$ & $18.58 \%$ & $23.68 \%$ & $25.63 \%$ & $6.07 \%$ & $5.92 \%$ & $10.67 \%$ & $16.29 \%$ \\
\hline & & SharpeR & 0.316 & 0.378 & -0.046 & -0.125 & 0.305 & 0.099 & -0.064 & -0.232 & -0.205 & 0.055 & -0.003 \\
\hline
\end{tabular}

Annualized return, volatility, and Sharpe Ratio of equally weighted (EW) and value-weighted (VW) top (T) and bottom (B) decile portfolios by different momentum measures (MoM) and long-short momentum portfolios of buying the top decile portfolio and short the bottom portfolio of the same MoM (T-B) and combination of different MoMs, including MaxMin that buys the top decide based on MoM(Max) and shorts the bottom decile based on MoM(Min), MinMax that buys the top decile based on MoM(Min) and shorts the bottom decile based on $\operatorname{MoM}(\operatorname{Max}), 75 / 25$ that buys the top of decile based on MoM(Q.75) and shorts the bottom decile of $\operatorname{MoM}\left(Q_{.25}\right)$, and 25/75 that buys the top decile based on $\operatorname{MoM}\left(Q_{.25}\right)$ and shorts the bottom decile based on MoM(Q.75). The sample is monthly CRSP universal stocks from January 1980 to December 2006. The look-back period is from t-12 and t-2 and portfolios are rebalanced every month. NYSE breakpoints are employed to form the decile portfolios. To calculate the Sharpe Ratio, the risk-free rate is assumed to be $5 \%$ per year.

Table 4. Correlations of long-short quantile momentum portfolios

\begin{tabular}{|c|c|c|c|c|c|c|c|c|}
\hline Weight & Variable & MoM(Mean) & MoM(SR) & MoM(Max) & $\operatorname{MoM}\left(Q_{.75}\right)$ & $\operatorname{MoM}\left(Q_{.50}\right)$ & $\operatorname{MoM}\left(Q_{.25}\right)$ & $\operatorname{MoM}(\operatorname{Min})$ \\
\hline \multirow{7}{*}{ VW } & MoM(Mean) & 1.000 & 0.910 & 0.355 & 0.614 & 0.921 & 0.596 & 0.242 \\
\hline & $\operatorname{MoM}(\mathrm{SR})$ & 0.910 & 1.000 & 0.240 & 0.504 & 0.903 & 0.682 & 0.360 \\
\hline & $\operatorname{MoM}(\operatorname{Max})$ & 0.355 & 0.240 & 1.000 & 0.834 & 0.213 & -0.409 & -0.686 \\
\hline & $\operatorname{MoM}(Q .75)$ & 0.614 & 0.504 & 0.834 & 1.000 & 0.502 & -0.133 & -0.489 \\
\hline & $\operatorname{MoM}\left(Q_{.50}\right)$ & 0.921 & 0.903 & 0.213 & 0.502 & 1.000 & 0.681 & 0.336 \\
\hline & $\operatorname{MoM}(Q .25)$ & 0.596 & 0.682 & -0.409 & -0.133 & 0.681 & 1.000 & 0.806 \\
\hline & MoM(Min) & 0.242 & 0.360 & -0.686 & -0.489 & 0.336 & 0.806 & 1.000 \\
\hline \multirow{7}{*}{ EW } & MoM(Mean) & 1.000 & 0.927 & -0.106 & 0.621 & 0.936 & 0.666 & 0.464 \\
\hline & $\operatorname{MoM}(\mathrm{SR})$ & 0.927 & 1.000 & -0.316 & 0.417 & 0.932 & 0.798 & 0.638 \\
\hline & $\operatorname{MoM}(\operatorname{Max})$ & -0.106 & -0.316 & 1.000 & 0.664 & -0.338 & -0.774 & -0.907 \\
\hline & $\operatorname{MoM}(Q .75)$ & 0.621 & 0.417 & 0.664 & 1.000 & 0.420 & -0.109 & -0.352 \\
\hline & $\operatorname{MoM}(Q .50)$ & 0.936 & 0.932 & -0.338 & 0.420 & 1.000 & 0.826 & 0.650 \\
\hline & $\operatorname{MoM}\left(Q_{.25}\right)$ & 0.666 & 0.798 & -0.774 & -0.109 & 0.826 & 1.000 & 0.948 \\
\hline & MoM(Min) & 0.464 & 0.638 & -0.907 & -0.352 & 0.650 & 0.948 & 1.000 \\
\hline
\end{tabular}

Coefficients of correlation among different Long-Short momentum portfolios (T-B in Table 3), under both equally weighted (EW) and value-weighted (VW) cases. Almost all correlations significantly differ from zero at $1 \%$.

\subsubsection{Performance and correlation of $\operatorname{MoM}\left(Q_{\theta}\right)$}

We report annualized return, volatility, and Sharpe Ratios for the top and bottom decile portfolios and the longshort portfolios in Table 3. We observe that the MoM(SR) top decile portfolio outperforms that of MoM(Mean) in both value-weighted and equally weighted portfolios by 13 bps and 135 bps in average return, respectively. On the other hand, risk-compensation improves the return of the valueweighted bottom decile by 227 bps over that of MoM(Mean) but is worse by 79 bps in the equally weighted portfolios. Consequently, $\mathrm{MoM}(\mathrm{SR})$ improves the return of the equally weighted long-short portfolio by 213 bps over that of $\operatorname{MoM}($ Mean), but is worse by 215 bps in value-weighted portfolios. 


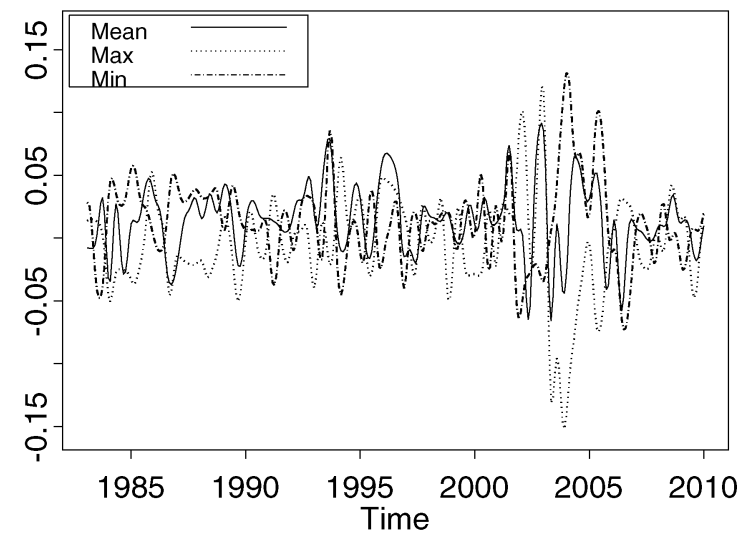

(a) $\operatorname{MoM}(\operatorname{Max})$ and $\operatorname{MoM}(\operatorname{Min})(\mathrm{VW})$

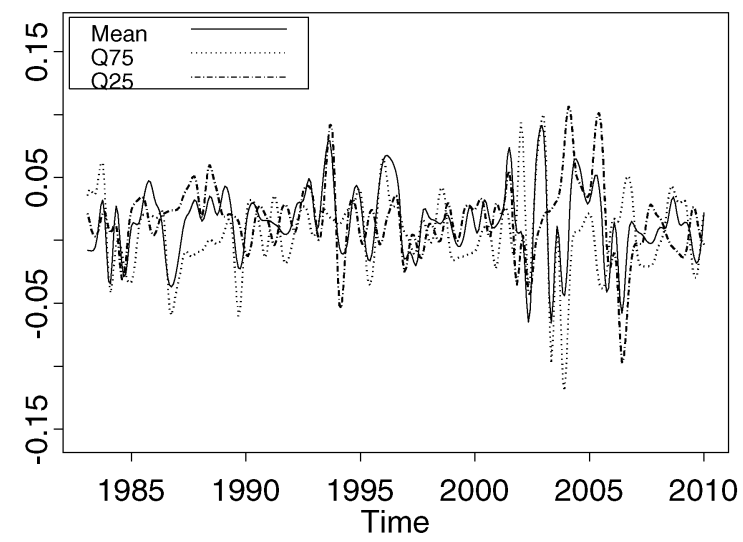

(c) $\operatorname{MoM}(\mathrm{Q} .75)$ and $\operatorname{MoM}(\mathrm{Q} .25)(\mathrm{VW})$

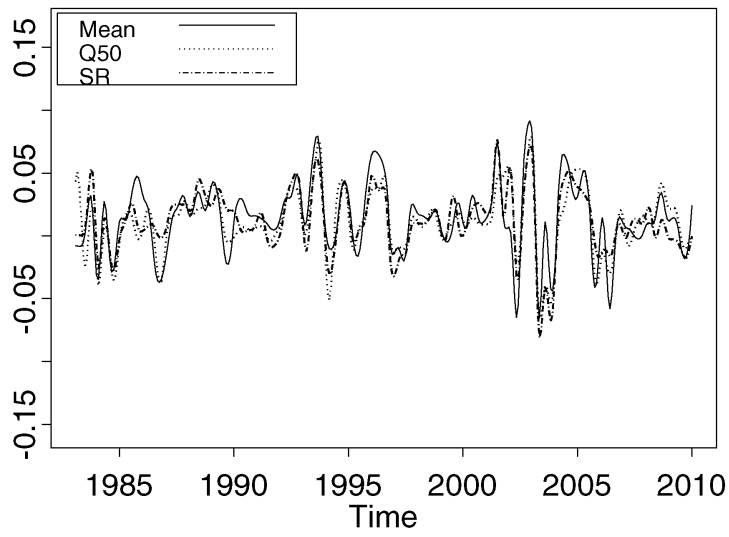

(e) $\operatorname{MoM}(\mathrm{SR})$ and $\operatorname{MoM}(\mathrm{Q} .50)(\mathrm{VW})$

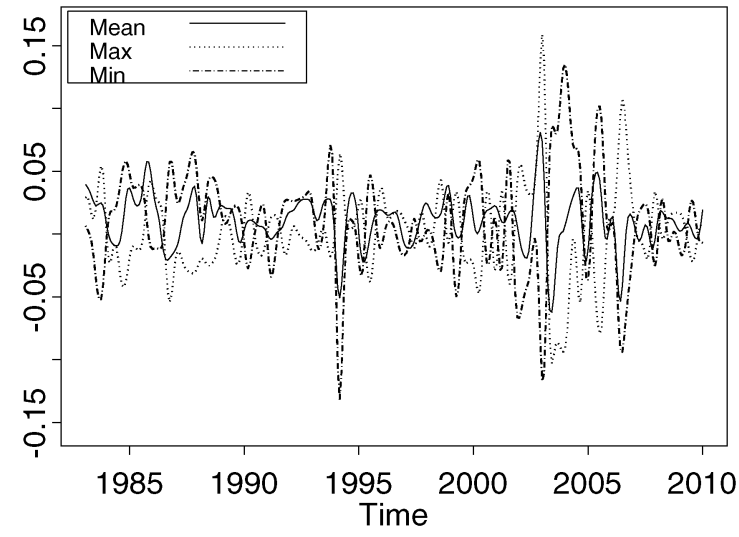

(b) $\operatorname{MoM}(\operatorname{Max})$ and MoM(Min) (EW)

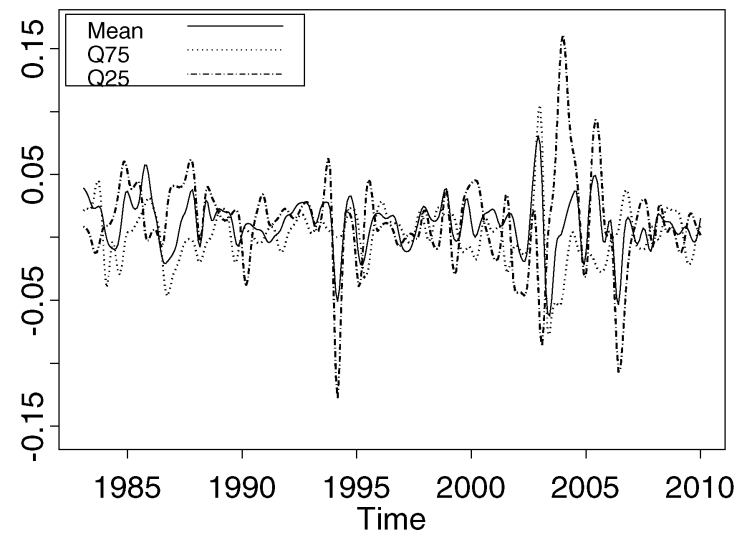

(d) $\operatorname{MoM}\left(\right.$ Q.75) and $\operatorname{MoM}\left(Q_{.25}\right)(\mathrm{EW})$

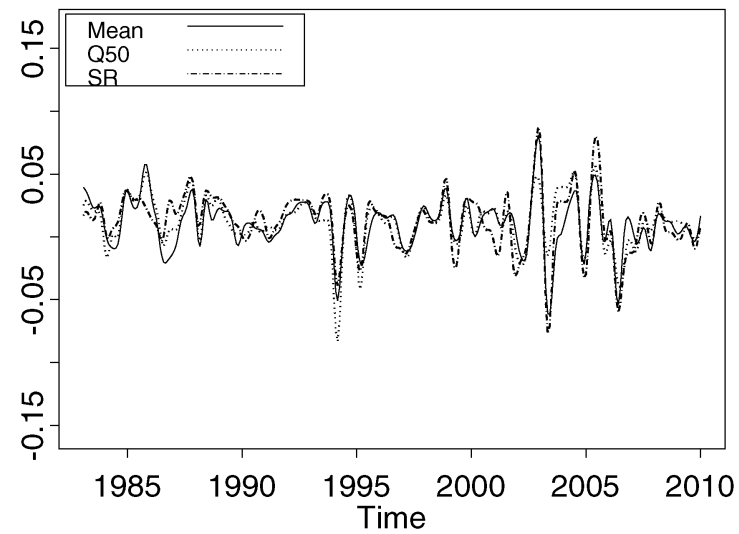

(f) $\operatorname{MoM}(\mathrm{SR})$ and $\operatorname{MoM}(\mathrm{Q} .50)$ (EW)

Figure 2. Plot of 36 months moving median return series of long-short momentum portfolios.

Table 3 shows that $\operatorname{MoM}\left(Q_{\theta}\right)$ tends to have smaller returns for the top decile portfolio but larger returns for the bottom decile portfolio than $\mathrm{MoM}($ Mean). However, we note that $\operatorname{MoM}\left(\mathrm{Q}_{25}\right)$ is the best among $\operatorname{MoM}\left(\mathrm{Q}_{\theta}\right)$ for a valueweighted portfolio and $\operatorname{MoM}\left(\mathrm{Q}_{.50}\right)$ is the best for an equally weighted portfolio. This indicates that momentum portfolios based on small $\theta$ may capture momentum information better for value-weighted portfolios.
Table 4 reports coefficients of correlation among the returns of long-short portfolios of different $\operatorname{MoM}\left(\mathrm{Q}_{\theta}\right)$ and the benchmarks. The different $\beta$ characteristics of $\operatorname{MoM}(\operatorname{Max})$ and $\operatorname{MoM}(\operatorname{Min})$ are well captured by their significant negative correlations -0.907 and -0.686 for equally weighted and value-weighted portfolios, respectively. Similarly, $\operatorname{MoM}\left(\mathrm{Q}_{.25}\right)$ and $\operatorname{MoM}\left(\mathrm{Q}_{.75}\right)$ also have significant but small negative correlations. The long-short portfolio of 


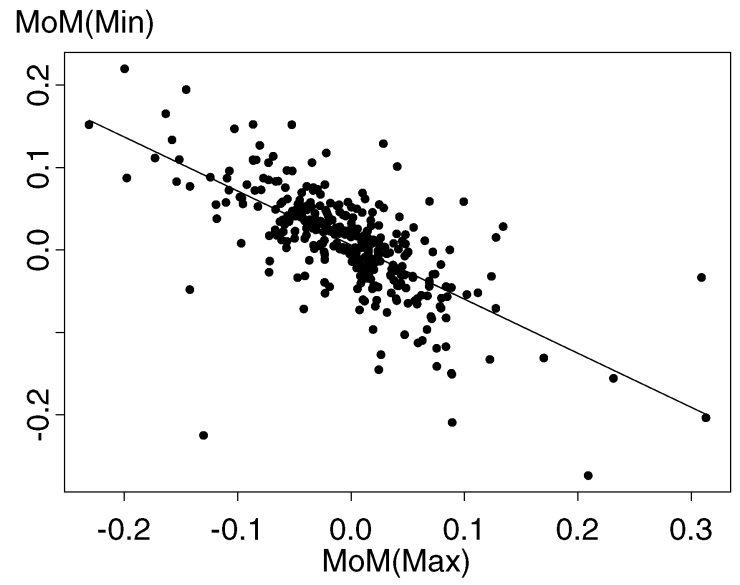

(a) $\operatorname{MoM}(\operatorname{Max})$ versus $\operatorname{MoM}(\operatorname{Min})(\mathrm{VW})$

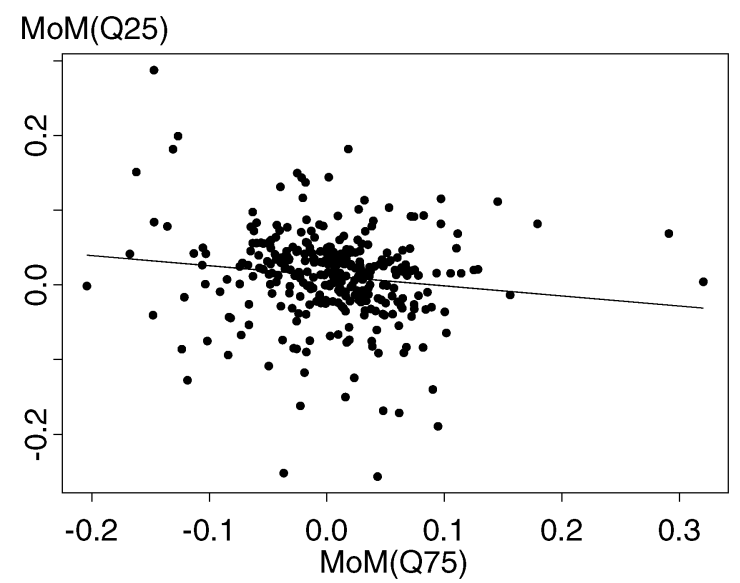

(c) $\operatorname{MoM}\left(Q_{.75}\right)$ versus $\operatorname{MoM}\left(\mathrm{Q}_{25}\right)$ (VW)

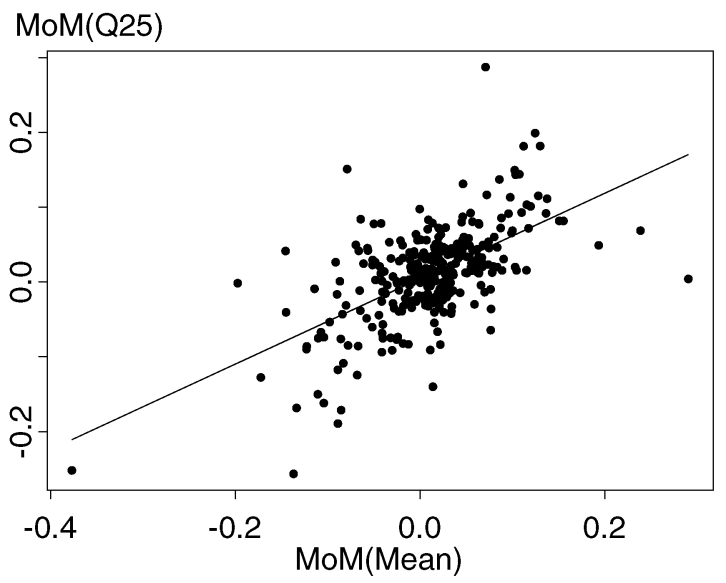

(e) $\operatorname{MoM}(\mathrm{SR})$ versus $\operatorname{MoM}(\mathrm{Q} .50)(\mathrm{VW})$

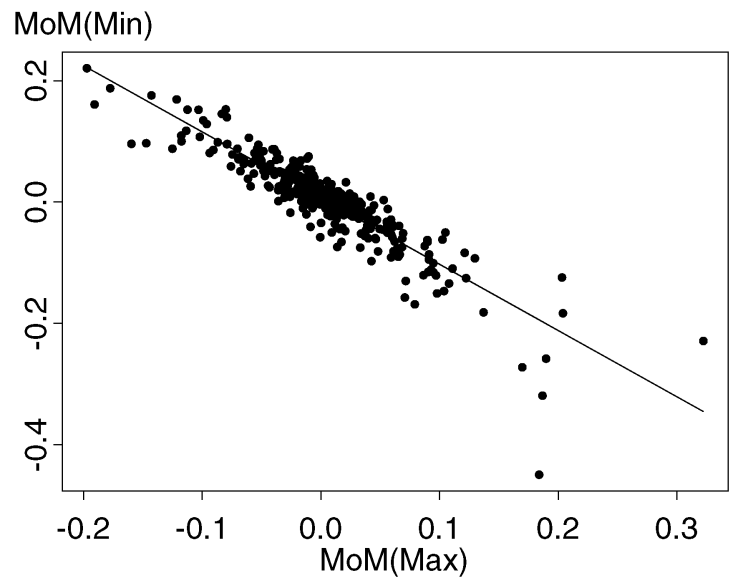

(b) $\operatorname{MoM}(\operatorname{Max})$ versus $\operatorname{MoM}(\mathrm{Min})$ (EW)

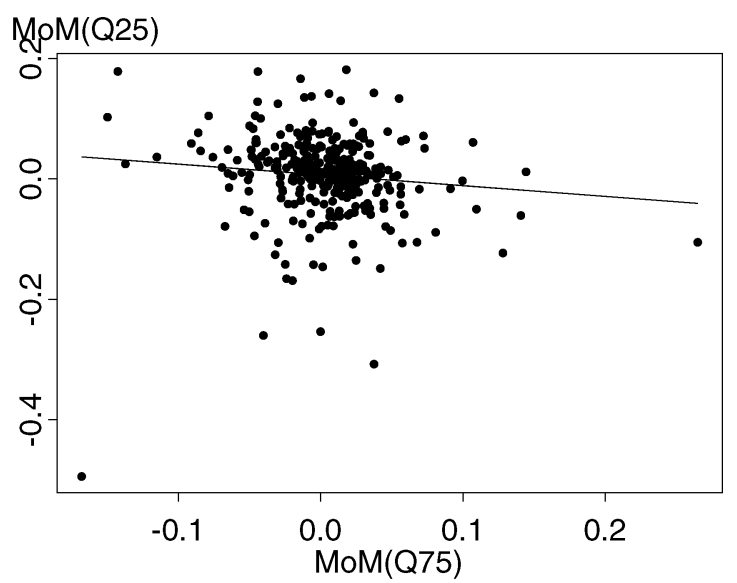

(d) $\operatorname{MoM}\left(Q_{.75}\right)$ versus $\operatorname{MoM}\left(Q_{.25}\right)(E W)$

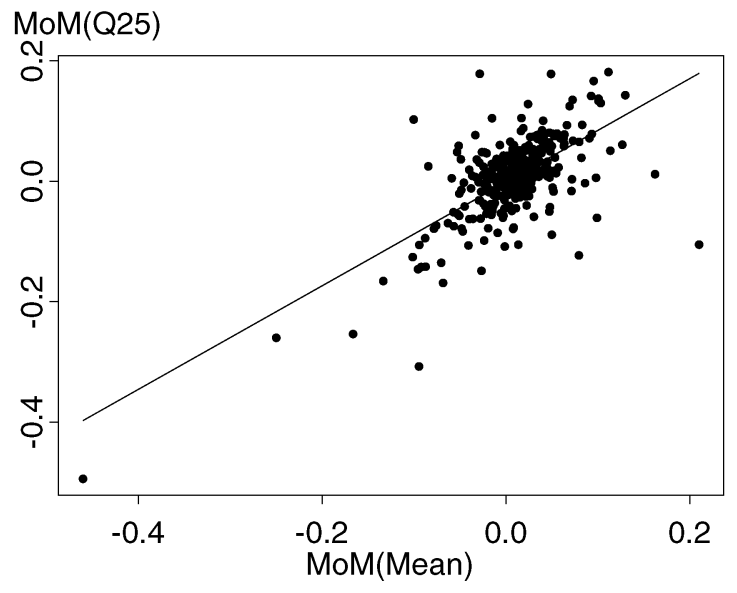

(f) $\operatorname{MoM}(\mathrm{SR})$ versus $\operatorname{MoM}(\mathrm{Q} .50)(\mathrm{EW})$

Figure 3. Scatter plots of selected return series of long-short quantile momentum portfolios.

$\operatorname{MoM}($ Mean) has high correlations with those of $\mathrm{MoM}(\mathrm{SR})$ and $\operatorname{MoM}\left(\mathrm{Q}_{50}\right)$ (that is, 0.910 and 0.921 for value-weighted portfolios and 0.927 and 0.936 for equally weighted portfolios), but small correlations with other $\operatorname{MoM}\left(\mathrm{Q}_{\theta}\right)$ portfolios.
We also plot the relationship of long-short momentum portfolios using different MoMs in Figures 2 and 3. Smoothed returns series in Figure 2 shows clear negative correlations between $\operatorname{MoM}(\operatorname{Max})$ and $\operatorname{MoM}(\operatorname{Min})$. 
Table 5.

\begin{tabular}{|c|c|c|c|c|c|c|c|c|c|c|c|c|c|}
\hline Weight & Portfolio & Statistics & MoM(Mean) & $\operatorname{MoM}(\mathrm{SR})$ & $\operatorname{MoM}(\operatorname{Max})$ & $\operatorname{MoM}(\mathrm{Q} .75)$ & $\operatorname{MoM}\left(Q_{.50}\right)$ & $\operatorname{MoM}\left(Q_{.25}\right)$ & MoM(Min) & MaxMin & MinMax & $75 / 25$ & $25 / 75$ \\
\hline \multirow{9}{*}{ VW } & \multirow{3}{*}{$\mathrm{T}$} & return & $18.81 \%$ & $18.94 \%$ & $15.78 \%$ & $16.82 \%$ & $19.18 \%$ & $19.91 \%$ & $18.84 \%$ & - & - & - & - \\
\hline & & Volatility & $22.20 \%$ & $17.98 \%$ & $25.77 \%$ & $24.15 \%$ & $22.19 \%$ & $19.52 \%$ & $17.89 \%$ & - & - & - & - \\
\hline & & SharpeR & 0.622 & 0.775 & 0.418 & 0.489 & 0.639 & 0.764 & 0.774 & - & - & - & - \\
\hline & \multirow{3}{*}{ B } & return & $4.09 \%$ & $6.36 \%$ & $10.76 \%$ & $8.62 \%$ & $5.21 \%$ & $3.38 \%$ & $3.98 \%$ & - & - & - & - \\
\hline & & volatility & $23.70 \%$ & $19.95 \%$ & $17.33 \%$ & $19.03 \%$ & $22.36 \%$ & $25.29 \%$ & $26.03 \%$ & - & - & - & - \\
\hline & & SharpeR & -0.039 & 0.068 & 0.332 & 0.190 & 0.010 & -0.064 & -0.039 & - & - & - & - \\
\hline & \multirow{3}{*}{ T-B } & return & $14.73 \%$ & $12.58 \%$ & $5.02 \%$ & $8.19 \%$ & $13.97 \%$ & $16.53 \%$ & $14.86 \%$ & $11.79 \%$ & $8.08 \%$ & $13.43 \%$ & $11.29 \%$ \\
\hline & & volatility & $22.32 \%$ & $20.54 \%$ & $21.98 \%$ & $20.37 \%$ & $19.65 \%$ & $21.08 \%$ & $21.45 \%$ & $15.76 \%$ & $19.15 \%$ & $18.48 \%$ & $19.84 \%$ \\
\hline & & SharpeR & 0.436 & 0.369 & 0.001 & 0.157 & 0.456 & 0.547 & 0.460 & 0.431 & 0.161 & 0.456 & 0.317 \\
\hline \multirow{9}{*}{ EW } & \multirow{3}{*}{$\mathrm{T}$} & return & $22.77 \%$ & $24.12 \%$ & $18.68 \%$ & $19.98 \%$ & $22.40 \%$ & $22.65 \%$ & $22.14 \%$ & - & - & - & - \\
\hline & & volatility & $23.32 \%$ & $17.20 \%$ & $25.30 \%$ & $24.16 \%$ & $22.54 \%$ & $19.82 \%$ & $17.15 \%$ & - & - & - & - \\
\hline & & SharpeR & 0.762 & 1.111 & 0.541 & 0.620 & 0.772 & 0.891 & 1.000 & - & - & - & - \\
\hline & \multirow{3}{*}{ B } & return & $11.97 \%$ & $11.18 \%$ & $13.42 \%$ & $12.25 \%$ & $11.51 \%$ & $11.31 \%$ & $11.93 \%$ & - & - & - & - \\
\hline & & volatility & $28.10 \%$ & $24.84 \%$ & $21.23 \%$ & $25.12 \%$ & $27.99 \%$ & $29.33 \%$ & $29.79 \%$ & - & - & - & - \\
\hline & & SharpeR & 0.248 & 0.249 & 0.397 & 0.288 & 0.233 & 0.215 & 0.233 & - & - & - & - \\
\hline & \multirow{3}{*}{ T-B } & return & $10.80 \%$ & $12.93 \%$ & $5.25 \%$ & $7.73 \%$ & $10.89 \%$ & $11.35 \%$ & $10.21 \%$ & $6.75 \%$ & $8.71 \%$ & $8.67 \%$ & $10.41 \%$ \\
\hline & & volatility & $18.33 \%$ & $21.01 \%$ & $14.72 \%$ & $15.27 \%$ & $17.39 \%$ & $20.75 \%$ & $22.63 \%$ & $11.64 \%$ & $18.27 \%$ & $14.44 \%$ & $19.50 \%$ \\
\hline & & SharpeR & 0.316 & 0.378 & 0.017 & 0.179 & 0.339 & 0.306 & 0.230 & 0.150 & 0.203 & 0.254 & 0.277 \\
\hline
\end{tabular}

Similar to Table 3, except all quantile MoMs are calculated using smoothed quantiles.

Table 6. Correlations of long-short smoothed quantile momentum portfolios $(k=4)$

\begin{tabular}{|c|c|c|c|c|c|c|c|c|}
\hline Weight & Variable & MoM(Mean) & $\operatorname{MoM}(\mathrm{SR})$ & MoM(Max) & $\operatorname{MoM}(Q .75)$ & $\operatorname{MoM}(Q .50)$ & $\operatorname{MoM}(\mathrm{Q} .25)$ & MoM(Min) \\
\hline \multirow{6}{*}{ VW } & MoM(Mean) & 1.000 & 0.910 & 0.685 & 0.835 & 0.915 & 0.833 & 0.717 \\
\hline & MoM(SR) & 0.910 & 1.000 & 0.592 & 0.754 & 0.867 & 0.856 & 0.778 \\
\hline & $\operatorname{MoM}(\operatorname{Max})$ & 0.685 & 0.592 & 1.000 & 0.907 & 0.694 & 0.380 & 0.165 \\
\hline & $\operatorname{MoM}\left(\mathrm{SQ}_{.50}\right)$ & 0.915 & 0.867 & 0.694 & 0.858 & 1.000 & 0.864 & 0.720 \\
\hline & $\operatorname{MoM}\left(\mathrm{SQ}_{.25}\right)$ & 0.833 & 0.856 & 0.380 & 0.595 & 0.864 & 1.000 & 0.921 \\
\hline & $\operatorname{MoM}(\operatorname{Min})$ & 0.717 & 0.778 & 0.165 & 0.409 & 0.720 & 0.921 & 1.000 \\
\hline \multirow{6}{*}{ EW } & $\operatorname{MoM}(\mathrm{SR})$ & 0.927 & 1.000 & 0.513 & 0.801 & 0.923 & 0.924 & 0.885 \\
\hline & $\operatorname{MoM}(\operatorname{Max})$ & 0.704 & 0.513 & 1.000 & 0.878 & 0.626 & 0.383 & 0.204 \\
\hline & $\operatorname{MoM}(\mathrm{SQ} .75)$ & 0.917 & 0.801 & 0.878 & 1.000 & 0.904 & 0.740 & 0.602 \\
\hline & $\operatorname{MoM}(\mathrm{SQ} .50)$ & 0.955 & 0.923 & 0.626 & 0.904 & 1.000 & 0.940 & 0.859 \\
\hline & $\operatorname{MoM}\left(\mathrm{SQ}_{.25}\right)$ & 0.893 & 0.924 & 0.383 & 0.740 & 0.940 & 1.000 & 0.972 \\
\hline & MoM(Min) & 0.804 & 0.885 & 0.204 & 0.602 & 0.859 & 0.972 & 1.000 \\
\hline
\end{tabular}

Similar to Table 4, except all quantile MoMs are calculated using smoothed quantiles. All correlations significantly differ from zero at $1 \%$.

Scatter plots and straight line fits for selected return series are shown in Figure 3. We find that $\operatorname{MoM}(\operatorname{Max})$ and $\operatorname{MoM}(\mathrm{Min})$ have a negative linear relationship and $\operatorname{MoM}\left(\mathrm{Q}_{.25}\right)$ and $\operatorname{MoM}($ Mean) have a positive linear relationship. As indicated by the coefficient of correlation, the relationship between $\operatorname{MoM}(\mathrm{Q} .75)$ and $\operatorname{MoM}\left(Q_{.25}\right)$ tends to be negative but insignificant.

Negative correlation of quantile momentum portfolios between left and right tails suggests ways of hedging and performance optimization. In Table 3, we also report the performance of mixed long-short portfolios that long the top decile of one MoM measure and short the bottom decile of another measure. We note that $75 / 25$ has the highest Sharpe Ratio 0.571 versus 0.436 of the long-short MoM(Mean) for value-weighted portfolios.

\subsubsection{Performance and correlation of $\operatorname{MoM}\left(\mathrm{SQ}_{\theta}\right)(k=4)$}

We report similar statistics for the smoothed versions of long-short momentum portfolios, $\operatorname{MoM}\left(\mathrm{SQ}_{\theta}\right)(k=4)$ in Tables 5 and 6 . First we note that the most profitable quantile momentum strategy $\mathrm{MoM}\left(\mathrm{SQ}_{25}\right)$ outperforms the MoM(Mean) by 180 bps for value-weighted portfolios and $55 \mathrm{bps}$ for equally weighted ones. $\mathrm{MoM}\left(\mathrm{SQ}_{.25}\right)$ has a larger Sharpe Ratio than MoM(Mean) by 0.111 for value-weighted portfolios but slightly smaller for the equally 


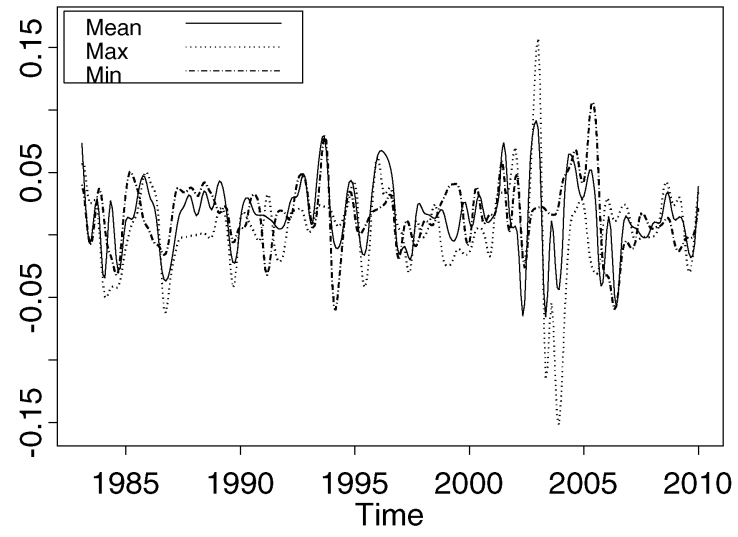

(a) $\operatorname{MoM}($ SMax) and MoM(SMin) (VW)

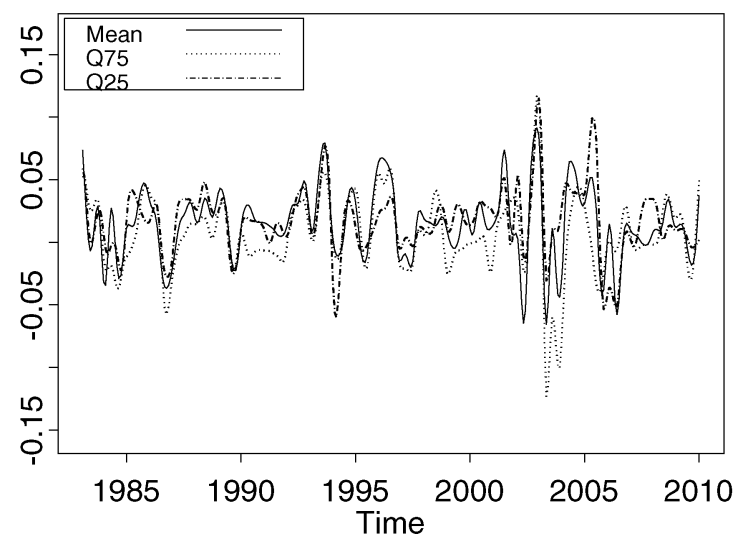

(c) $\operatorname{MoM}\left(\mathrm{SQ}_{.75}\right)$ and $\operatorname{MoM}\left(\mathrm{SQ}_{25}\right)(\mathrm{VW})$

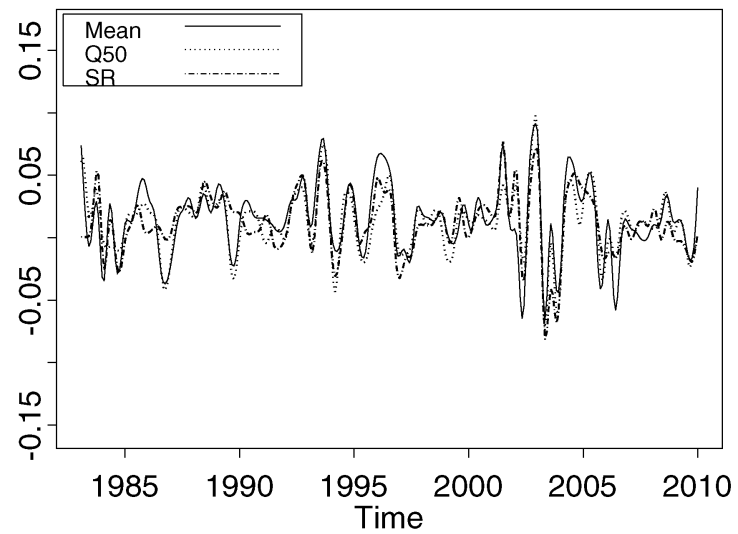

(e) $\operatorname{MoM}($ Mean $)$ and $\operatorname{MoM}\left(\mathrm{SQ}_{25}\right)(\mathrm{VW})$

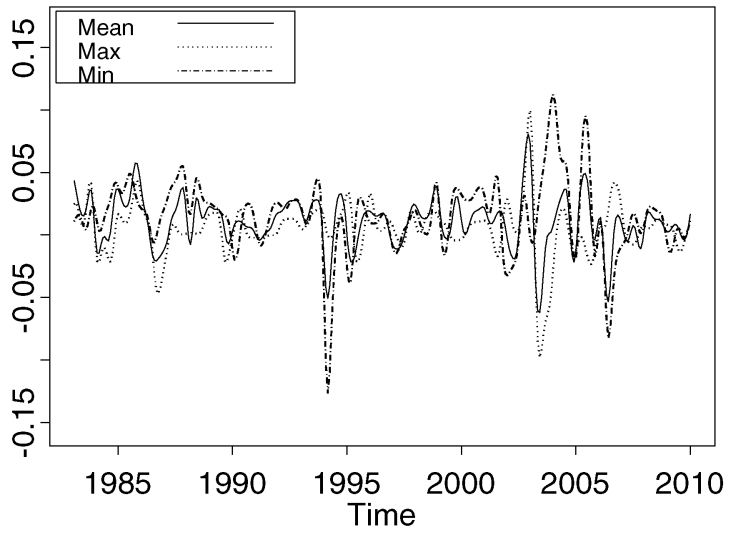

(b) MoM(SMax) and MoM(SMin) (EW)

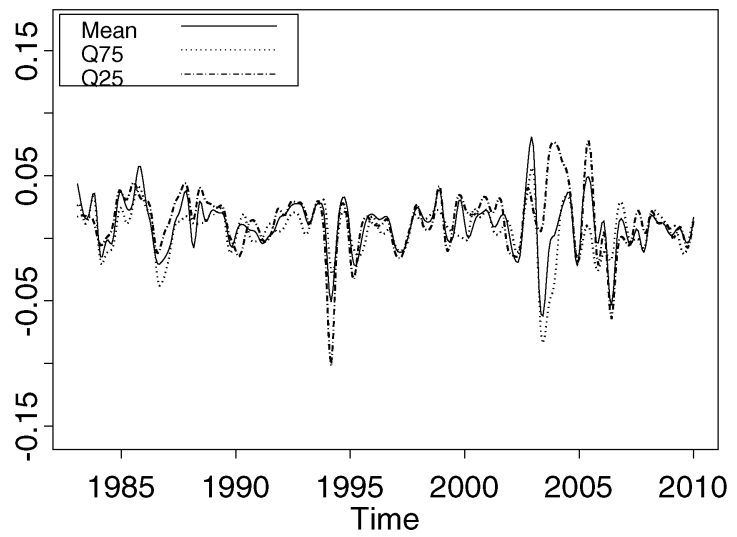

(d) $\operatorname{MoM}\left(\mathrm{SQ}_{.75}\right)$ and $\operatorname{MoM}\left(\mathrm{SQ}_{25}\right)$ (EW)

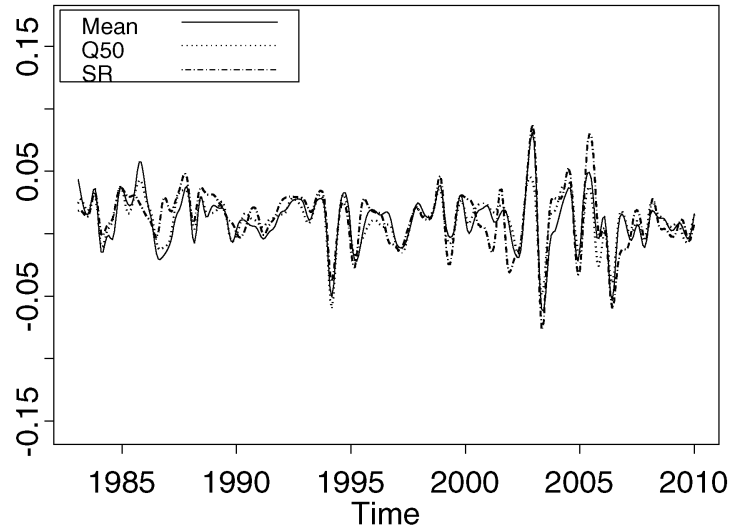

(f) $\operatorname{MoM}($ Mean) and MoM(SQ.25) (EW)

Figure 4. Plot of 36 months moving median return series of long-short smooth quantile momentum portfolios $(k=4)$.

weighted ones. This shows that smoothed quantile momentum strategies improve the performances of momentum portfolios.

Table 6 shows that smoothing also removes the negative correlation that was seen between $\operatorname{MoM}(\operatorname{Max})$ and $\operatorname{MoM}(\mathrm{Min})$. One possible reason is that the distribution of returns in the look-back window shrinks toward the mean after smoothing. Consequently, the correlation between MoM(SMax) and MoM(SMin) increases as both are more correlated with MoM(Mean). The change of this structure is also confirmed by Figures 4 and 5 .

Furthermore, $\operatorname{MoM}\left(\mathrm{SQ}_{.25}\right)(k=4)$ is approximately beta neutral compared with $\operatorname{MoM}\left(\mathrm{Q}_{.25}\right)$. $\operatorname{MoM}\left(\mathrm{SQ}_{.25}\right)(k=4)$ is the best on average with less $\beta$-sensitivity. 


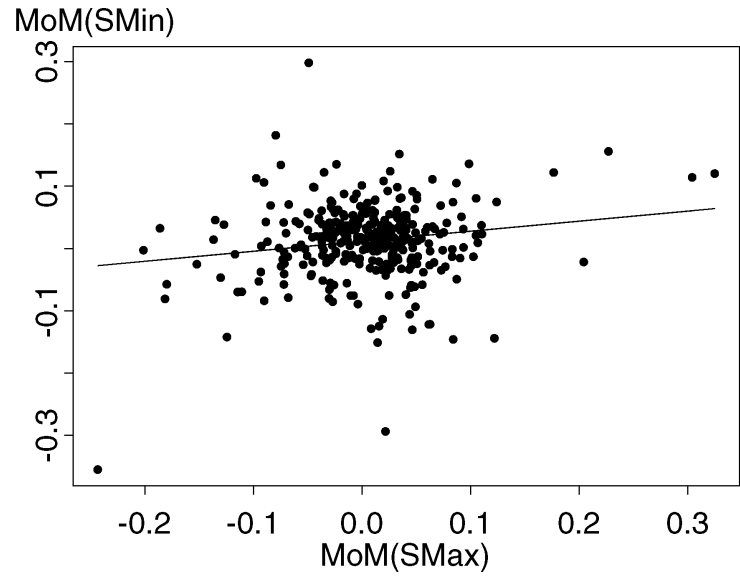

(a) $\operatorname{MoM}($ SMax) versus MoM(SMin) (VW)

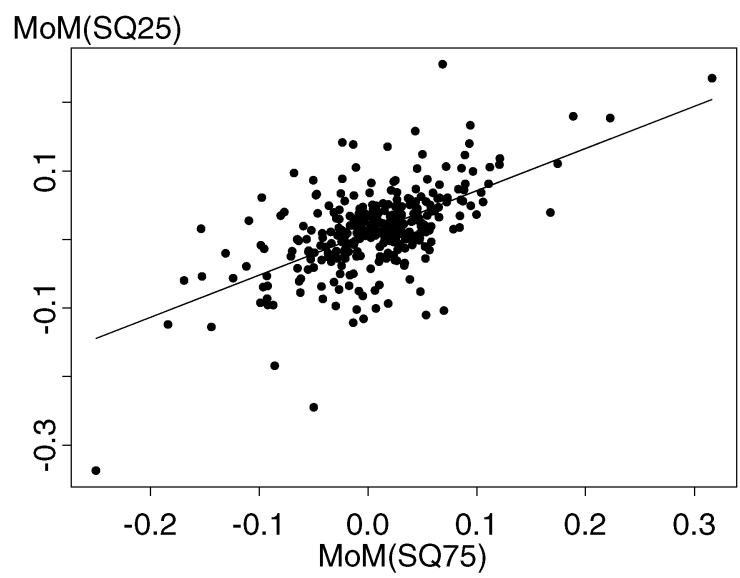

(c) $\operatorname{MoM}\left(\mathrm{SQ}_{.75}\right)$ versus $\mathrm{MoM}\left(\mathrm{SQ}_{.25}\right)$ (VW)

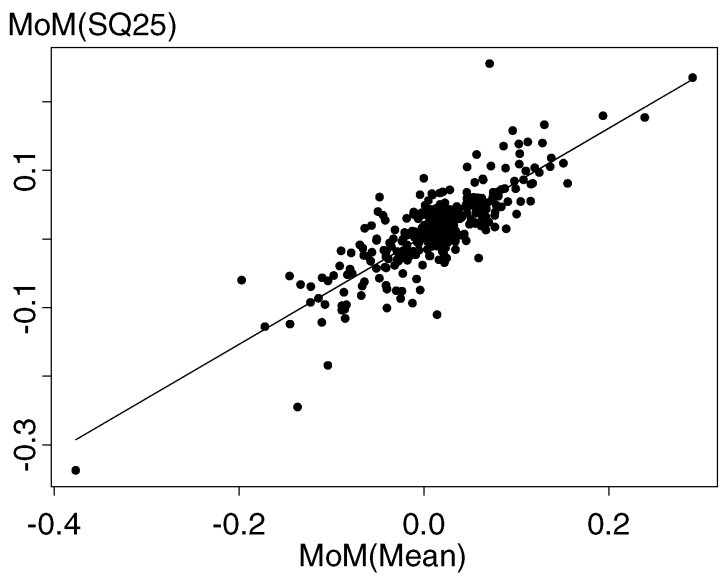

(e) $\operatorname{MoM}($ Mean) versus MoM(SQ.25) (VW)

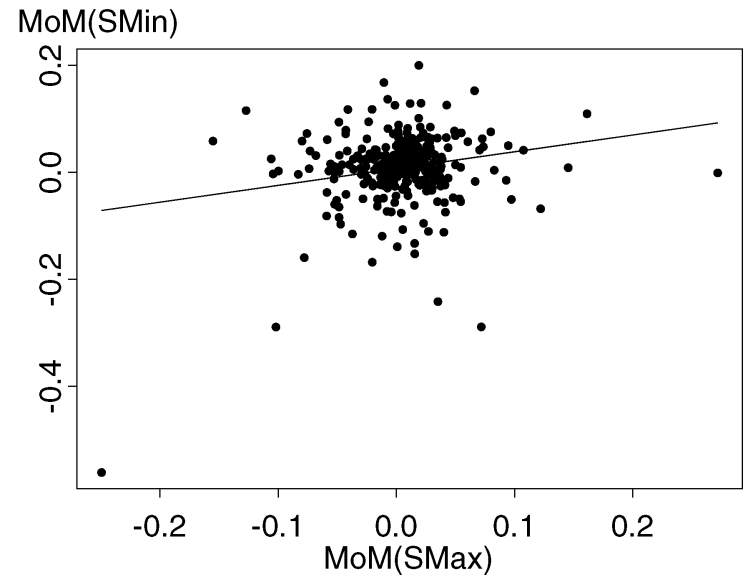

(b) $\operatorname{MoM}($ SMax) versus MoM(SMin) (EW)

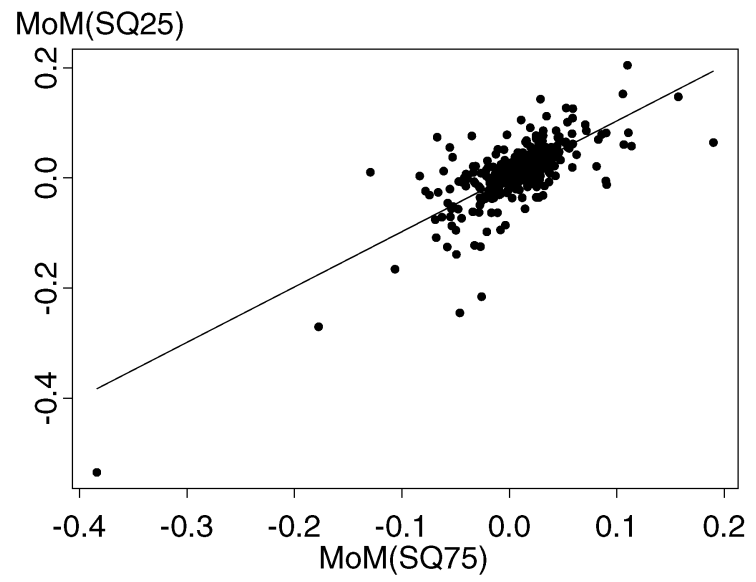

(d) $\operatorname{MoM}\left(S_{.75}\right)$ versus MoM(SQ.25) (EW)

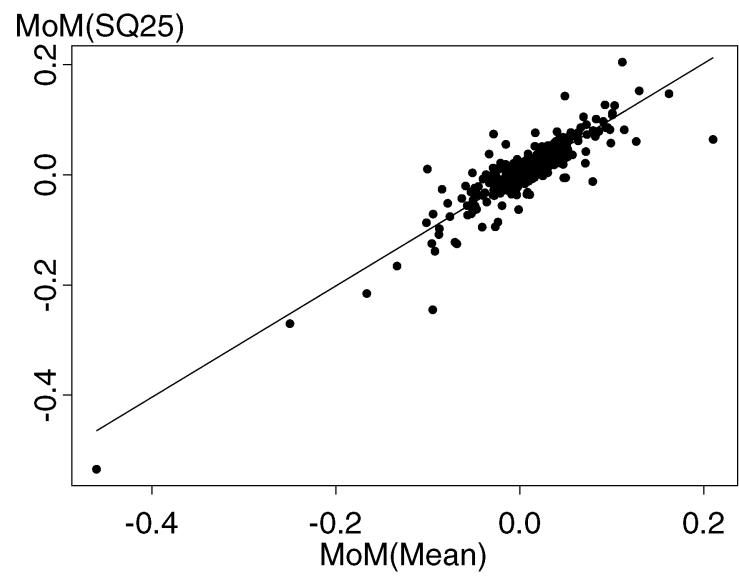

(f) $\operatorname{MoM}\left(\right.$ Mean) versus $\operatorname{MoM}\left(\mathrm{SQ}_{.25}\right)(\mathrm{EW})$

Figure 5. Scatter plots of selected return series of long-short quantile momentum portfolios $(k=4)$.

\section{CONCLUSION}

In this paper, we introduce a new set of momentum measures based on quantile and locally smoothed quantile estimates. The distribution of recent returns contains more information than the simple average and can lead to alternative measures of momentum. The properties of the proposed quantile MoMs are discussed under a simple one-factor CAPM model. It is shown that $\operatorname{MoM}(\operatorname{Max})$ and 
$\operatorname{MoM}(\operatorname{Min})$ are more $\beta$ dependent than the usual average measure. We also propose a smoothed version of quantile momentum $\operatorname{MoM}\left(\mathrm{SQ}_{\theta}\right)$, which tends to be less beta dependent. Empirical performance based on the alternative MoMs is presented. We find that some of the $\operatorname{MoM}\left(\mathrm{SQ}_{\theta}\right)$ portfolios outperform the MoM(Mean) for both equally weighted portfolios and value-weighted portfolios. The best long-short portfolio is $\operatorname{MoM}\left(\mathrm{SQ}_{.25}\right)$ with a smoothing window size 4. Our findings call for additional theoretical work to explain the momentum anomaly. The new measures also suggest new trading strategies for equity traders and fund managers to exploit the momentum.

\section{ACKNOWLEDGEMENT}

The authors gratefully acknowledge the insightful comments and suggestions from the Editor, an Associate Editor and one referee, which resulted in significant improvement of the paper.

Received 11 January 2008

\section{REFERENCES}

Fama, Eugene F. and French, Kenneth R. (1996). Multifactor explanations of asset pricing anomalies. The Journal of Finance $\mathbf{5 1}$ 55-84.

George, Thomas J. and Hwang, Chuan-Yang (2004). The 52-week high and momentum investing. The Journal of Finance LIX 21452176.

Jegadeesh, NARAsimhan (1990). Evidence of predictable behavior of security returns. The Journal of Finance 45 881-898.

Jegadeesh, Narasimhan and Titman, Sheridan (1993). Returns to buying winners and selling losers: Implications for stock market efficiency. The Journal of Finance 48 65-91.
Jegadeesh, Narasimhan and Titman, Sheridan (2001). Profitability of momentum strategies: An evaluation of alternative explanations. The Journal of Finance 56 699-720.

Lehmann, Bruce N. (1990). Fads, martingales, and market efficiency, The Quarterly Journal of Economics 105 1-28.

LEVy, Robert A. (1967). Relative strength as a criterion for investment selection. The Journal of Finance 22 595-610.

LeWELlen, Jonathan (2002). Momentum and autocorrelation in stock returns. The Review of Financial Studies 15 533-563.

Lo, Andrew W. and MacKinlay, A. Craig (1990). When are contrarian profits due to stock market overreaction? The Review of Financial Studies 3 175-205.

Moskowitz, Tobias J. and Grinblatt, Mark (1999). Do industries explain momentum? The Journal of Finance 54 1249-1290.

Poterba, James M. and Summers, Lawrence H. (1988). Mean reversion in stock prices: Evidence and implications. Journal of Financial Economics 22 27-59.

Rachev, Svetlozar, Jašić, Teo, Stoyanov, Stoyan, and Fabozzi, FrANK J. (2007). Momentum strategies based on rewardcrisk stock selection criteria. Journal of Banking and Finance 31 2325-2346.

Yongchang Feng

Department of Business Statistics and Econometrics

Guanghua School of Management

Peking University

Rong Chen

Department of Statistics

Rutgers University

New Brunswick, NJ, USA

and

Department of Business Statistics and Econometrics

Peking University

E-mail address: rongchen@stat.rutgers.edu

Gilbert W. Bassett

Department of Finance

University of Illinois at Chicago 